\title{
RESIDÊNCIAS MULTIPROFISSIONAIS EM SAÚDE: FORMAÇÃO OU TRABALHO?
}

\author{
RESIDENCES MULTIDISCIPLINARY HEALTH:
}

EDUCATION OR JOB?

Terezinha de Fátima Rodrigues ${ }^{1}$

\section{RESUMO}

Este artigo efetua a reflexão sobre os Programas de Residências Multiprofissionais em Área Profissional de Saúde aprofundando elementos da ambiguidade existente em sua natureza: formação ou trabalho. Traz aspectos desta inserção, em tempos de precarização tanto da formação quando do trabalho e seus impactos no cotidiano dos residentes. Se coloca na perspectiva de refletir alguns dos desafios colocados aos Programas nesta modalidade de formação profissional.

PALAVRAS-CHAVE: Residências Multiprofissionais. Saúde. Formação. Trabalho.

\begin{abstract}
This article makes a reflection on the multi-professional Residency Program in Health Professional Area deepening elements of ambiguity existing in nature: training or work. Brings aspects of this insertion in precarious times as much training when the work and its impact on the daily lives of residents. It puts in perspective to reflect some of challenges' programs in this type of training.
\end{abstract}

KEYWORD: Multidisciplinary Residence. Health. Training academic education. Job.

\footnotetext{
${ }^{1}$ Universidade Federal de São Paulo/Campus Baixada Santista. Professora no Curso de Serviço Social e no Programa de Pós-Graduação em Serviço Social e Políticas Sociais. Tutora e docente no Programa de Residência Multiprofissional Redes de Atenção Psicossocial. Avaliadora Nacional dos Programas de Residência Multiprofissional (MEC) e Representante da ABEPSS na Câmara Técnica (4) - Saúde Mental na Comissão Nacional de Residências Multiprofissionais em Saúde (CNRMS). Telefone 13 98165-8793 E-mail: terezinha.unifesp@gmail.com.
} 


\section{INTRODUÇÃO}

Os Programas de Residência Multiprofissional em Área Profissional de Saúde foram criados pela Lei $n^{0} 11.129$ de 2005, com ênfase na formação de trabalhadores para o Sistema Único de Saúde (SUS). Nascem articulados e de maneira estratégica, em conjunto com os Ministérios da Saúde (MS) e Educação (MEC), coordenados pela Comissão Nacional de Residência Multiprofissional em Saúde (CNRMS).

Ainda que a consolidação desta estratégia, considerada inovadora tanto no campo da formação quanto no trabalho ocorra a partir de 2005, registram-se experiências importantes, como as da década de 1990, com projetos na Atenção Primária de Saúde por meio do Departamento de Atenção Básica da Secretaria de Assistência à Saúde, pertencente ao MS (CAMPOS, 2008).

A partir de 2002, as Residências Multiprofissionais em Saúde (RMS) passam a compor o Projeto ReforSUS², que culmina na criação da Secretaria de Gestão do Trabalho e Educação na Saúde (SGTES), em 2003. A SGTES busca articular ações e políticas no sentido da educação permanente dos trabalhadores do SUS, com o MEC, o Ministério do Trabalho e Emprego (MTE), secretarias estaduais e municipais de saúde e educação, trabalhadores, instituições formadoras, docentes, estudantes, movimentos sociais e conselhos de saúde (MATHIAS, 2011).

Esta iniciativa, articulada a outras previstas legalmente, como no artigo 27 da Lei Orgânica de Saúde (LOS) abre possibilidades para diferentes estratégias na área da educação permanente no SUS, sendo uma delas, os Programas de Residência Multiprofissional em Saúde, agregando as áreas profissionais, consideradas da saúde 3 .

Art. 27. A política de recursos humanos na área da saúde será formalizada e executada, articuladamente, pelas diferentes esferas de

\footnotetext{
${ }^{2}$ Projeto de Reforço à Reorganização do Sistema Único de Saúde (REFORSUS). Iniciativa do governo brasileiro, destinada a obter financiamento internacional para viabilizar as reformas que estavam sendo introduzidas no SUS. Submetido à apreciação dos bancos financiadores, Banco Mundial e Interamericano foi avaliado e resultou, em maio de 1996, no Relatório de Avaliação do Projeto de Reforma do SUS. O relatório descrevia o setor saúde no país, analisando os seus principais problemas e apresentava a estratégia governamental para enfrentá-los (KARAM, 2002).

3 Biologia, Biomedicina. Educação Física, Enfermagem, Farmácia, Fisioterapia, Fonoaudiologia, Medicina, Medicina Veterinária, Nutrição, Odontologia, Psicologia, Serviço Social e Terapia Ocupacional. Resolução 287/98. Conselho Nacional de Saúde.
} 
governo, em cumprimento dos seguintes objetivos: I - organização de um sistema de formação de recursos humanos em todos os níveis de ensino, inclusive de pós-graduação, além da elaboração de programas de permanente aperfeiçoamento de pessoal (BRASIL, 1990).

Em 2005, por meio da Lei Federal $n^{0}$ 11.129, o MEC e o MS instituem a CNRMS no âmbito do Ministério da Educação (BRASIL, 2005; 2006a), abrindo campo para a regulamentação da Residência Multiprofissional em Saúde, considerada estratégica na consolidação de uma política de formação de recursos humanos para a saúde, consonantes com os princípios e diretrizes do SUS.

Em relação à natureza destes Programas, a Portaria Interministerial nº 45 destaca ser essa, uma modalidade de ensino, em caráter de pós-graduação Lato Sensu, destinada às áreas profissionais não médicas, relacionadas à saúde.

A Portaria Interministerial $n^{0} 1.077$ de 12/11/2009 aponta os princípios orientadores para as propostas, com ênfase na inserção em cenários de atuação que representem a realidade do país em termos sanitários, a concepção de saúde ampliada, a construção de estratégias e abordagens que insiram os residentes nas condições reais em que se efetivam a política de saúde, o compartilhamento de saberes e práticas, objetivando a constituição das competências compartilhadas importante para a educação permanente e para estabelecer mudanças nos processos de trabalho, formação e gestão na saúde. Portarias subsequentes consolidam o arcabouço legal dos Programas.

\section{PROGRAMAS DE RESIDÊNCIA MULTIPROFISSIONAL: EM DISCUSSÃO A FORMAÇÃO}

Conforme Cecim (2005), a Educação Permanente em Saúde, ao mesmo tempo em que disputa pela atualização cotidiana das práticas insere-se em uma construção de relações e processos que vão do interior das equipes em atuação conjunta às práticas interinstitucionias e/ou intersetoriais, implicando as políticas nas quais se inscrevem.

Com isto, pode corresponder à educação em serviço, quando esta coloca a pertinência dos conteúdos, instrumentos e recursos para a formação; pode corresponder à Educação Continuada, quando esta pertence à construção objetiva de quadros institucionais e à investidura de carreiras por serviço e pode corresponder à educação 
formal de profissionais, quando esta se apresenta na realidade concreta em que se efetiva o trabalho profissional e coloca-se em aliança a projetos integrados entre o setor/mundo do trabalho e o setor/mundo do ensino (CECIM, 2005).

Consideramos que os Programas de Residência Multiprofissional abarcam estas três dimensões e contemplam a inserção dos residentes na vivência concreta dos serviços, inseridos no campo da política de saúde.

Os Programas potencializam a transformação das práticas e com esta intencionalidade, movimenta uma rede composta pelos demais trabalhadores. Problematiza e tensiona elementos da política social que ocorre nos espaços cotidianos das práticas profissionais e na gestão e controle social, com possibilidades do fechamento de um ciclo altamente potencializador a uma formação na concepção apontada por Cecim (2005). Ressalta-se, porém, que isto vem ocorrendo de forma desafiadora aos que acreditam na potência de propostas de tal natureza.

Refletir sobre a formação implica apontar outros sujeitos, com destaque para todos os trabalhadores, sejam docentes e tutores, sejam os vinculados aos serviços, integrantes dos Programas. Implica refletir o "mundo da formação" e o "mundo dos serviços”. Mas, de que “mundos” estamos falando?

A formação como processo presente nos Programas de Residência oportuniza análises inicialmente voltadas aos projetos pedagógicos e a dimensão teórico-política articulada às intencionalidades. Destaca-se que as propostas devem estar vinculadas aos interesses e necessidades do SUS e pressupostos presentes na Política Nacional de Saúde (Lei N. o 8.080/1990).

Outro ponto importante é o papel das instituições formadoras e das Associações/Conselhos Profissionais que definem/defendem determinado projeto de formação em suas respectivas áreas profissionais.

O "mundo da formação" nos remete aos espaços presentes nas Instituições Formadores, no caso específico dos Programas de Residência, às Instituições de Ensino Superior que ofertam os Programas ${ }^{4}$, mais especificamente, as Universidades. E aí nos perguntamos: que características estão presentes nestes espaços? Como refletir sobre o trabalho docente? Trabalho docente que, em alguns projetos pedagógicos se insere

\footnotetext{
${ }^{4}$ Resolução CNRMS n ${ }^{\circ}$ 2, de 4 de maio de 2010.

Serv. Soc. \& Saúde, Campinas, SP v. 15, n. 1 (21), p. 71-82, jan./jun. 2016 ISSN 1676-6806
} 
duplamente: na condição de docente e de tutor, com incisiva participação na definição das ações /articulação das atividades.

Ainda que com resistências de coletivos que acreditam e lutam por uma educação pública, de qualidade e socialmente referenciada, o viés meritocrático e do produtivismo acadêmico impera, com índices e pontuações que produzem e reproduzem a intensificação ${ }^{5}$ do trabalho. Consideramos que esta perspectiva fortalecida pelo viés meritocrático, assentado em exigências cada vez maiores em termos de produtivismo acadêmico, fragiliza iniciativas com viés extensionista, como as relativas aos Programas de Residência.

Outro elemento ao se pensar a formação, é o relativo às Associações/Conselhos Profissionais que dentre suas normativas, tem o de regulamentação das profissões. Aqui nos parece central pensar a direção política presente nas diretrizes tanto no campo da formação quanto no trabalho profissional e as possibilidades presentes nos Programas de Residência.

Ressaltam-se as possibilidades de uma formação, na modalidade lato sensu, que caminha na construção de práticas que agreguem o trabalho articulado (sem perder de vista as especificidades) com outras áreas/conhecimentos, ou seja, na perspectiva multi/interprofissional.

Com isto, consideramos que as Associações/órgãos profissionais são sujeitos políticos fundamentais nas discussões sobre os desafios presentes nestas iniciativas e atentos aos pressupostos presentes nas áreas e à direção ético-política desta modalidade de formação.

Ressalta-se que os projetos de formação das áreas profissionais são importantes no sentido do direcionamento /dimensão ética a eles inerentes. Programas de residência voltados à construção multiprofissional oportunizam ampliar a formação, onde o

\footnotetext{
${ }^{5}$ Conforme Dal Rosso (2016) reserva-se a categoria de produtividade para a obtenção de resultados superiores em qualidade e quantidade, decorrentes de investimentos em tecnologias materiais inovativas e organizativas que não requeiram maior consumo das energias pessoais. Por outro lado, a categoria de intensidade refere-se ao esforço gasto pelos indivíduos no processo de trabalho. A intensidade tem a ver com o investimento das energias das pessoas com o trabalho. Refere-se ao desgaste da pessoa com o trabalho. Disponível em: http://cienciaecutura.bvs.br/pdf. Acesso em 12/01/2016.
} 
trabalho em equipe abre possibilidades de construção teórico-prática, sem perder de vista a especificidade presente na formação de origem.

O que potencializa Programas como os de Residência Multiprofissional é a possibilidade do trabalho conjunto, a construção de ações “costuradas” por diferentes áreas profissionais, sendo que o que as une, neste caso, é a defesa de uma determinada política, qual seja, a pública, voltada à defesa do SUS e da saúde como direito.

\section{PROGRAMAS DE RESIDÊNCIA MULTIPROFISSIONAL: EM DISCUSSÃO O TRABALHO}

A inserção na rede de serviços supõe a integração ensino-serviço, compreendido pelo trabalho coletivo pactuado, articulado e integrado envolvendo residentes, docentes e trabalhadores que integram as equipes. Esta inserção coloca em aberto, os desafios deste denominado "mundo dos serviços", que preferimos ampliar para o "mundo do trabalho" (ANTUNES, 1998).

"Mundo do trabalho” como um conjunto de transformações que vêm ocorrendo, principalmente após o último quartel do século XX, quando o capitalismo enfrenta mais uma de suas crises que abalam as certezas até então vigentes e altera substancialmente a materialidade e a subjetividade daqueles que vivem do trabalho. A crise instalada propiciou inúmeras transformações, dentre estas, a reestruturação produtiva do capital, sendo um de seus aspectos, a precarização com a desregulamentação do uso da força de trabalho.

A quadra histórica pós anos 1990 propiciou a ofensiva neoliberal, baseada em políticas de ajuste, na defesa da desregulamentação da entrada e saída de capitais dos países, na redução dos gastos públicos, na privatização das empresas públicas, na desregulamentação dos direitos, na defesa de um Estado parco para os “gastos” sociais, na estabilidade monetária como meta primordial, na disciplina orçamentária.

Estes elementos reforçam a análise sobre a precarização do trabalho, marcada pelas constantes investidas nos direitos conquistados pelos trabalhadores, materializada na desregulamentação das leis trabalhistas e dos contratos de trabalho e na expansão da terceirização. Aponta inúmeros desafios aos trabalhadores, dentre estes, a precarização 
do trabalho, a terceirização, a fragilidade/quebra de direitos trabalhistas com fragilizações e/ou inexistência de Planos de Carreira.

Impossível não nos referenciar a como estas mudanças trazem rebatimentos diretos no campo da política social e, especificamente, do trabalho em suas expressões cotidianas.

No campo da política social e mais especificamente, no campo da política de saúde, os anos 1990 e os 2000 em diante vão sofrer o redirecionamento do papel do Estado, influenciado pelo ajuste neoliberal.

Conforme Bravo (1999), a proposta de Política de Saúde da década de 1980 (Projeto de Reforma Sanitária) foi sucessivamente sendo desconstruída. A crescente vinculação da saúde aos interesses privatistas (mercado) possibilitou a fragilização do SUS, e dentre as questões que comprometeram este avanço, destaca-se

O desrespeito ao princípio da equidade na alocação dos recursos públicos pela não unificação dos orçamentos federal, estaduais e municipais; afastamento do princípio da integralidade, ou seja, indissolubilidade entre prevenção e atenção curativa havendo prioridade para a assistência médico-hospitalar em detrimento das ações de promoção e proteção da saúde (BRAVO, op. cit., p.12).

No transcorrer histórico da construção do SUS, inserido em uma política pública de saúde, tem-se processos articulados às transformações do mundo do trabalho com consequências centrais aos trabalhadores, dentre estas, condições objetivas de trabalho, com ausência/insuficiência de recursos humanos, materiais e financeiros que desafiam o trabalho, oportunizando rotinas e protocolos de atendimento que muitas vezes reproduzem práticas mecanicistas e autoritárias, ainda fortemente marcadas pelo modelo biomédico.

O redirecionamento das políticas sociais traz fortes implicações para as condições de trabalho, com salas sem condições de sigilo, móveis antigos, ausência de equipamentos e de condições de registro, falta de manutenção, de material de consumo e de investimento em bens de capital e equipamentos (BEHRING, 2009). Tem-se também, condições de salário e carreira estagnados oportunizando o desânimo e descrédito na possibilidade de alteração das práticas. 
Este cenário, do concreto presente na órbita do trabalho, impacta nas relações que perpassam iniciativas como as dos Programas de Residência. A inserção de equipes de residentes neste âmbito oportuniza tensões de diferentes naturezas.

Inicialmente, equipes de residentes compostas com áreas profissionais que não estão presentes nos serviços. Com a concepção das contradições que perpassam o real, esta questão pode, potencialmente, ser uma riqueza, pois a interação entre as equipes que passam a compor o conjunto de trabalhadores nos serviços, potencializa a reflexão, e ao agregar novos sujeitos exige uma recomposição, um aprendizado e articulações que envolve a todos.

Por outro lado, pode trazer expectativas de que, aquele profissional, necessário no campo da política de saúde, venha a suprir a ausência daquela área, inserindo-se em uma condição diferenciada, mais marcada pela execução das demandas dos serviços em detrimento à condição de formação. O peso maior centra-se no trabalho e não na formação.

Outra questão é a extensa carga horária prevista para os Programas. Uma modalidade lato sensu, voltada à “formação em serviços”, em dois anos, com uma carga horária de 60 horas semanais, em regime de dedicação exclusiva. Desta carga horária apontam-se as atividades práticas, teóricas e teórico-práticas, acrescidas do Trabalho de Conclusão de Curso. No final, o residente deve totalizar 5.760 horas.

Observa-se que esta condição traz várias implicações. Inicialmente o desafio dos projetos político pedagógicos dos Programas em adequar esta normatividade à realidade concreta dos serviços. Ressalta-se a natureza de alguns Programas de Residência, dentre estes, os ligados à Atenção Primária em Saúde, em que os serviços não funcionam em horário integral. Ainda que funcionem, nos parece importante uma problematização mais ampla: a natureza dos programas de residência multiprofissional - formação em serviços - que devem prezar por espaços mais criativos, de trocas e articulação dos serviços em rede, na perspectiva da prestação com qualidade aos usuários do SUS.

Sessenta horas semanais implica a intensificação do trabalho dos residentes e segue contrária a luta mais geral dos trabalhadores quanto à carga horária de 30 horas semanais. Consideramos esta discussão necessária nos espaços organizativos e 
instâncias legais dos Programas de Residência para a construção de outros marcos legais que avancem na perspectiva de revisão desta extensa carga horária.

Outra questão que merece atenção é a própria modalidade do trabalho em equipe multiprofissional. O trabalho multi/interprofissional é desafiante na medida em que está presente outra lógica: a das trocas, conversas, reuniões, articulações das ações e não deve estar no horizonte apenas da equipe de residentes, inserida em determinado espaço sócio-ocupacional.

Deve ser uma diretriz presente no trabalho de todos os profissionais da saúde. E aí, outro desafio está posto! Como envolver a equipe, diante de um cenário como o descrito, de insuficiência de recursos humanos, de intensificação do trabalho, de práticas protocolares e muitas vezes, rotineiras? Equipe de trabalhadores que vivenciam a precarização do trabalho e renda e com uma remuneração, em alguns casos, menor que a dos residentes. Esta questão não é menor e tem que ser enfrentada, pois ainda que, permeada por silêncios, aparece sob a forma de diferentes tensões no cotidiano do trabalho.

Há os que acreditam que os residentes devem suprir a necessidade imediata de recursos humanos, reproduzindo procedimentos e respondendo as demandas dos serviços, inseridos na equipe dos trabalhadores. Pelas condições em que se efetiva o trabalho, destacadas anteriormente, a presença do residente nos serviços tem se tornado desafiante na medida em que a expectativa é de sua inserção como “mais um” a compor ou "substituir" o quadro de trabalhadores daquele local.

Esta linha é tênue, pois o residente, considerado um profissional graduado, tem as condições do exercício de sua profissão. Não há impedimentos para esta ação e isto está previsto nos Programas: a atuação profissional/multi/interprofissional. Com isto, de um lado, o trabalho; de outro, os Programas de Residências como iniciativas articuladas na perspectiva da formação em serviços. E este cuidado deve ser preservado!

Ainda que possa atuar no sentido de suas competências e atribuições específicas, o residente não pode ser considerado um membro da equipe que responde individualmente pelas demandas.

Há uma inserção diferenciada e a articulação com a formação exige supervisão das práticas, horários para estudos, reflexões, reuniões, vivências nas experiências de 
trabalhos em rede, possibilidade de encontros que ampliem o leque de reflexões e conhecimentos, retornando sob a forma de novas possibilidades e estratégias de educação permanente que reverbere na transformação de modelos e modos de operar em saúde.

Devem ser preservados os espaço para as discussões em equipe, a possibilidade da articulação de um trabalho integrado o que impõe saídas das Unidades, o conhecimento do território e a articulação com as atividades na Universidade. Ainda que necessários, os horários e escalas nos serviços não podem ser colocados de maneira rígida, sem a perspectiva de se coadunar com a natureza de um espaço de formação sustentada nas propostas dos Programas de Residência.

\section{CONSIDERAÇÕES FINAIS}

Pela natureza das Residências Multiprofissionais em Área de Saúde - formação em serviços - há uma inserção diferenciada e dúbia dos residentes nos serviços.

Não são estudantes, mas estão em processo de formação e devem estar amparados pelas instituições formadoras em todo o percurso formativo, com destaque para a mediação ensino-serviços, a perspectiva teórica e ético-política presente nos projetos político-pedagógicos dos Programas, a necessária supervisão e articulação das atividades e, fundamentalmente, os vínculos com os preceptores, sujeitos dos serviços que acompanham o cotidiano dos residentes.

Não são trabalhadores dos espaços sócio-ocupacionais onde os Programas se realizam, mas estão aptos ao exercício da profissão naquele espaço.

Tem sido recorrente, nos espaços de discussão e Fóruns de Residências (locais ou nacionais), a denúncia de residentes, da vivência do assédio moral pela exigência do trabalho (voltado à sua especificidade), e responsabilidade pelo atendimento direto das demandas daquela Unidade/serviço em detrimento do componente da formação.

Isto se materializa na ausência de espaço para a preceptoria, reuniões de discussão em equipe, tensionamentos nas relações residentes - equipe de serviços preceptoria - com acirramentos e disputas que se generalizam oportunizando a vivência do assédio moral e respectivo adoecimento dos residentes. 
Esta situação que é grave deve ser enfrentada agregando as instituições formadoras, os coletivos de residentes que se organizam, local e nacionalmente, e as Associações/Conselhos Profissionais.

Recebido em 30.03.2016 - Aprovado em 06.06.2016

\section{REFERÊNCIAS}

ANTUNES, R. Adeus ao Trabalho? Ensaio sobre as Metamorfoses e a Centralidade do Mundo do Trabalho. São Paulo. Cortez, 1998.

BEHRING. E. R. Política Social no contexto da crise capitalista. In: CFESS, ABEPSS. Serviço Social - Direitos e Competências Profissionais. Brasília, DF: CFESS ABEPSS. 2009. http://welbergontran.com.br/cliente/uploads/ Acesso em 03/03/2016.

BRASIL. Comissão Nacional de Residência Multiprofissional em Saúde. Resolução $\mathbf{n}^{\mathbf{0}}$ 2, de 4 de maio de 2010. Dispõe sobre a organização, o funcionamento e as atribuições da Comissão de Residência Multiprofissional (COREMU) das instituições que oferecem programas de residência multiprofissional ou em área profissional da saúde. Brasília (DF), 2010.

BRASIL. Lei no 8.080 de 19 de setembro de 1990. Lei Orgânica da Saúde. Brasília (DF), 1990.

BRASIL. Lei $\mathbf{n}^{\mathbf{0}}$ 11.129/05. Institui as residências multiprofissionais e em área profissional da saúde. Brasília (DF), 2005.

BRASIL. Ministério da Saúde. Resolução 287/98. Dispõe sobre as categorias profissionais de saúde de nível superior para fins de atuação do Conselho de Saúde. Brasília (DF), 1998.

BRASIL. Ministério da Saúde. Secretaria de Gestão do Trabalho e da Educação na Saúde. Departamento de Gestão da Educação na Saúde. Residência multiprofissional em saúde: experiências, avanços e desafios. Brasília: Ministério da Saúde, Série B. Textos Básicos de Saúde, 2006a. 414 p.

BRASIL. Portaria Interministerial n. ${ }^{0}$ 2.117/05. Institui a Residência multiprofissional em Saúde. Ministério da Saúde. Ministério da Educação, Brasília (DF), 2005.

Serv. Soc. \& Saúde, Campinas, SP v.15, n. 1 (21), p. 71-82, jan./jun. 2016 ISSN 1676-6806 
BRASIL. Portaria interministerial $\mathbf{n}^{\mathbf{0}}$ 45, de 12 de janeiro de 2007. Dispõe sobre a Residência Multiprofissional em Saúde e a Residência em Área Profissional da Saúde e Institui a Comissão Nacional de Residência Multiprofissional em Saúde. Ministério da Saúde. Ministério da Educação. Diário Oficial da União. 15 jan. 2007; Seção 1:28, 2007.

BRASIL. Portaria Interministerial $\mathbf{n}^{\circ} \mathbf{1 . 0 7 7}$, de 12/11/2009. Institui a Comissão Nacional de Residência Multiprofissional em Saúde. Ministério da Saúde. Ministério da Educação. Brasília (DF), 2009.

BRAVO; M. I. S. Política de Saúde no Brasil. Serviço Social e Saúde: Formação e Trabalho Profissional. São Paulo: Cortez, 2006:1-24.

file://C:/Users/Rosana/Downloads/politica-de-saude-no-brasil-por-maria-ines-souzabravo/ Acesso em 06/03/2016.

CAMPOS, G. W. S. et. al. Reflexões sobre a Atenção Básica e a Estratégia de Saúde da Família. In: CAMPOS, G.W. S.; GUERREIRO, A. V. P. (Org.) Manual de práticas de atenção básica: saúde ampliada e compartilhada. São Paulo: Aderaldo \& Rothschild, 2008, p. 132-153.

CECCIM, R. B. Educação permanente: desafio ambicioso e necessário. InterfaceComunic. Saúde e Educ. v. 9, n.16: p.161-177, 2005.

DAL ROSSO, S. Jornada de Trabalho: Duração e Intensidade. http://cienciaecutura.bvs.br/pdf. Acesso em 12/01/2016.

KARAM, R.A.S. Modernização gerencial: um caminho obrigatório par a consolidação e o fortalecimento do Sistema Único de Saúde. A experiência do Projeto REFORSUS. (Dissertação de Mestrado). Fundação Getúlio Vargas: Escola Brasileira de Administração Pública. Rio de Janeiro, 2002.

MATHIAS, M. Gestão da educação e do trabalho em saúde no centro do debate. RET SUS, Brasília (DF), 2011, p. 10-13. 